\title{
Deep brain stimulation for Tourette syndrome: a single-center series
}

\author{
Richard S. Dowd, MD, ${ }^{1}$ Michael Pourfar, MD, ${ }^{2}$ and Alon Y. Mogilner, MD, PhD² \\ 'Department of Neurosurgery, Tufts Medical Center, Boston, Massachusetts; and ${ }^{2}$ Department of Neurosurgery, New York \\ University Langone Medical Center, New York, New York
}

\begin{abstract}
OBJECTIVE Tourette syndrome (TS) is a complex neuropsychiatric disorder characterized by multiple motor and phonic tics. While pharmacological and behavioral therapy can be effective in most patients, a subset of patients remains refractory to treatment. Increasing clinical evidence from multiple centers suggests that deep brain stimulation (DBS) of the medial thalamus can be effective in many cases of refractory TS.

METHODS The authors retrospectively reviewed outcomes in 13 patients with refractory TS who underwent medial thalamic DBS performed by their team over a 7-year period. Patients were evaluated by a multidisciplinary team, and preoperative objective assessments were performed using the Yale Global Tic Severity Scale (YGTSS) and Yale-Brown Obsessive Compulsive Scale. YGTSS scores were calculated at visits immediately postoperatively and at the most recent follow-up in patients with a minimum of 6 months of postoperative follow-up. Coordinates of the active DBS contacts were calculated and projected onto each patient's pre- and postoperative images.
\end{abstract}

RESULTS Patients showed an average decrease of $37 \%(p=0.0063)$ in the total tic severity at their first postoperative visit. At their latest visit, their scores achieved significance, decreasing from preoperative scores by an average of $50 \%$ $(p=0.0014)$. The average position of the active contact was noted to be at the junction of the posterior ventralis oralis internus/centromedian-parafascicular nuclei. Device-related complications occurred in 2 patients, necessitating additional surgeries. All patients continued to use the system at last follow-up.

CONCLUSIONS The authors' data are consistent with the small but growing body of literature supporting DBS of the ventralis oralis internus/centromedian-parafascicular thalamus as an effective and relatively safe treatment for severe, refractory TS.

https://thejns.org/doi/abs/10.3171/2016.10.JNS161573

KEY WORDS Tourette syndrome; deep brain stimulation; medial thalamus; Yale Global Tic Severity Scale; YGTSS; Yale-Brown Obsessive Compulsive Scale; YBOCS; functional neurosurgery

$\mathrm{G}$ ILLES de la Tourette syndrome (TS) is a disorder characterized by involuntary motor and phonic tics, which typically begin in early childhood. While most cases can be managed medically or attenuate in adulthood, a subset of patients has extremely severe and refractory symptoms that result in significant injury and social isolation. ${ }^{7,41}$ For some of these patients who have not responded to a number of pharmacological and cognitive interventions, deep brain stimulation (DBS) has been repeatedly demonstrated to be safe and effective. An increasing number of reports have shown that DBS can dramatically reduce the number of tics in medically refractory TS. ${ }^{1-3,8-12,16,18,20,21,23,25,29,35,42}$ However, debate re- mains concerning many aspects of the procedure. While recent recommendations for inclusion and exclusion criteria have been put forth, ${ }^{35}$ the ideal target(s) remain a matter of debate, ${ }^{28}$ with 9 different regions postulated to provide potential benefit via interruption of a putative TS circuit. 13,17,22,31 The majority of case reports focus mainly on the subregions of the centromedian thalamus or globus pallidus internus (GPI). ${ }^{20,33,40}$ Our center selected the medial thalamic target (centromedian-parafascicular nucleus/ventralis oralis internus/substantia periventricularis), based on the preponderance of positive case reports supporting its efficacy. ${ }^{1,232,34,37,38}$ We report here our surgical and clinical experience with 13 patients over a period of 7

ABBREVIATIONS CM-PF = centromedian-parafascicular; DBS = deep brain stimulation; GPI = globus pallidus internus; OCD = obsessive-compulsive disorder; TS = Tourette syndrome; $\mathrm{VOI}=$ ventralis oralis internus; YBOCS = Yale-Brown Obsessive Compulsive Scale; YGTSS = Yale Global Tic Severity Scale.

SUBMITTED June 12, 2016. ACCEPTED October 31, 2016.

INCLUDE WHEN CITING Published online April 7, 2017; DOI: 10.3171/2016.10.JNS161573. 
years. We further explored the specific regions of stimulation that appear to correlate with symptomatic improvement.

\section{Methods}

We conducted a retrospective review of all patients with TS who underwent thalamic DBS performed by our team (Table 1). Of 15 patients who underwent surgery between January 2009 and May 2016, 13 consecutive patients with at least 6 months of follow-up were included. Before undergoing surgery, all patients were screened by an experienced movement disorders neurologist and stereotactic neurosurgeon familiar with DBS and the management of TS. Patients were assessed using the Yale Global Tic Severity Scale (YGTSS), the Yale-Brown Obsessive Compulsive Scale (YBOCS), and formal neuropsychological evaluation. ${ }^{14,23}$ A complete assessment of treatment modalities was reviewed. Patients were required to have tried a course of cognitive behavioral therapy, 1 alpha adrenergic agonist, and at least 3 dopamine receptor-blocking medications with either adequate dosages or limiting side effects. Significant psychiatric comorbidities, including debilitating obsessive-compulsive disorder (OCD) and/ or depression, were considered relative contraindications pending further psychiatric evaluation. A minimum age of 16 years in cases of self-injury or 18 years in the absence of self-injury was used. All cases were subsequently reviewed by a multidisciplinary committee comprising 2 psychiatrists $(1$ pediatric psychiatrist in patients $<18$ years old), a neuropsychologist, 2 neurosurgeons, and 2 movement disorder neurologists familiar with the diagnosis and management of TS. All operations were performed by the same neurosurgeon (A.Y.M.), and the deep brain stimulator was programmed by the same neurologist (M.P.); some patients underwent additional follow-up programming at outside medical centers. Institutional review board approval was obtained for the retrospective chart review as well as for subsequent administration of a brief questionnaire.

\section{Surgical Technique}

The DBS implantation was performed as a multistage procedure. ${ }^{4}$ A few weeks prior to surgery, stereotactic MRI was performed under general anesthesia in order to minimize head movement. Preliminary target and trajectory planning was then performed using the Brainlab stereotactic system (Brainlab $\mathrm{AB}$ ). The indirect coordinates for the electrode tip were chosen at $5 \mathrm{~mm}$ lateral to the midline, $4 \mathrm{~mm}$ posterior, and $0 \mathrm{~mm}$ superior to the midcommissural plane, ${ }^{1}$ corresponding to the substantia periventricularis. Entry angles ranged from $45^{\circ}$ to $65^{\circ}$ in the sagittal plane and from $25^{\circ}$ to $38^{\circ}$ lateral in the coronal plane.

The MR images were fused the day of surgery with thin-cut $(0.6$ or $1 \mathrm{~mm})$ CT-scan images obtained after placement of the stereotactic frame (Leksell, Elekta AB). Surgery was performed with the patient under conscious sedation (6 patients) or general anesthesia (7 patients). Microelectrode recordings were obtained intraoperatively, starting at $15 \mathrm{~mm}$ above the stereotactic target (Alpha-
Omega Engineering). Test stimulation, either macrostimulation through the microelectrode sheath $(3 \mathrm{~mm}$ above the tip) or direct stimulation through the DBS electrode, was performed to assess for side effects. In no cases did test stimulation lead to repositioning of the lead. All patients underwent bilateral implantation with DBS leads (model 3387, Medtronic). The pulse generators (bilateral single channel in 11 patients, dual channel in 2 patients) were placed under general anesthesia either the same day (2 patients), or within 14 days following lead placement. A high-resolution CT scan was obtained immediately postoperatively in all patients. In addition, 2 patients underwent postoperative high-resolution MRI. The postoperative images were then fused with the preoperative data set to identify the actual stereotactic coordinates of the lead contacts.

\section{Postoperative Care}

Initial programming typically began approximately 2 weeks after the DBS implantation at the first postoperative visit. Each electrode was evaluated using a pulse width of $90 \mu \mathrm{sec}$, a frequency of $130 \mathrm{~Hz}$, and steadily increasing voltages up to $4 \mathrm{~V}$ or less, depending on tolerability. The initially selected active electrode was either the one associated with subjective improvement or, in the absence of immediate benefit (as was more commonly the case), the most ventral, best tolerated electrode. During followup visits, the settings were adjusted according to perceived benefit or side effects, typically with increasing voltages followed by addition of adjacent electrodes or higher pulse width in patients who were not robustly responding. Patients usually received voltage in the range of $1-2 \mathrm{~V}$, which they could adjust on their own between visits. The patients were closely monitored for side effects and serious adverse events, usually monthly initially and then every 3-6 months after the 3rd month depending on proximity and need. At each visit, the patient's YGTSS score was usually calculated and, where appropriate, the YBOCS score was calculated as well. All patients also participated in 2-question telephone surveys administered from 6 to 74 months after the procedure. The first question was to rate their current symptoms on the Clinical Global Impression scale, ${ }^{15}$ and the second question was to answer the query, "Knowing what you know now, would you have the surgery again?" The preoperative and postoperative YGTSS and YBOCS scores were compared and, along with the answers to the survey questions, served as measures of efficacy.

The preoperative scores were compared with postoperative scores using a Wilcoxon signed-rank test. Patients served as their own controls, with preoperative YGTSS scores being compared with those obtained at the initial and the most recent follow-up visits. A Pearson correlation coefficient was calculated for the individual subscores compared with the overall improvement in YGTSS score. Preoperative YBOCS scores were compared only to the latest follow-up visit and were not performed in 1 patient who denied OCD symptoms. Given the sample size and the multiple tests involved, a $\mathrm{p}<0.01$ was considered significant. All calculations were performed using the SPSS statistical software package (IBM). 
TABLE 1. Characteristics of the 13 patients with TS

\begin{tabular}{|c|c|c|c|c|c|c|c|c|}
\hline Case No. & Age at Onset of TS (yrs) ${ }^{*}$ & Age at Op & Initial YGTSS Score† & OCD & ADD & Depression & Anxiety & Self-Injurious Behavior \\
\hline 1 & 6 & 16 & 39 & No & No & No & No & No \\
\hline 2 & 7 & 17 & 100 & Yes & No & Yes & Yes & Yes \\
\hline 3 & 6 & 21 & 67 & No & Yes & No & No & No \\
\hline 4 & 3 & 16 & 88 & Yes & Yes & Yes & Yes & Yes \\
\hline 5 & 6 & 19 & 95 & Yes & Yes & Past & No & Past \\
\hline 6 & 11 & 17 & 94 & Yes & Yes & Yes & No & Yes \\
\hline 7 & 3 & 18 & 91 & No & No & Past & Yes & Past \\
\hline 8 & 4 & 24 & 85 & Yes & Yes & No & Yes & Past \\
\hline 9 & 7 & 19 & 92 & Yes & No & Yes & Yes & No \\
\hline 10 & 3 & 19 & 95 & Yes & Yes & No & Yes & Past \\
\hline 11 & 16 & 33 & 74 & Yes & Yes & Yes & Yes & No \\
\hline 12 & 7 & 24 & 88 & Yes & No & Yes & Yes & Yes \\
\hline 13 & 9 & 16 & 95 & Yes & Yes & No & No & Yes \\
\hline
\end{tabular}

$\mathrm{ADD}=$ attention deficit disorder.

* When symptoms were first noticed by the parent or patient.

$\dagger$ Preoperative TS-related symptom severity.

\section{Results}

Patients had a mean follow-up time of 23 months (range 6-58 months). The mean improvement in the YGTSS score was $50 \%$ compared with preoperative testing ( $\mathrm{p}=$ 0.0014). All patients demonstrated improvement in their symptoms due to DBS therapy, although degrees of improvement ranged from $16 \%$ to $100 \%$ based on change in YGTSS score (Fig. 1 upper). Improvement of greater than $30 \%$ was seen in $84 \%$ of patients, and improvement greater than $50 \%$ was noted in $55 \%$ of patients. One patient, who had the the mildest tic severity at baseline, remained virtually tic free at the last follow-up, and 3 additional patients with more marked baseline severity reported minimal tic activity at the last follow-up. No patient reported an increase in tic severity at the latest follow-up post-DBS, although intervisit tic severity varied considerably in some patients (Fig. 1 lower). The YGTSS data also showed a significant difference between the preoperative scores and the first follow-up visit $(p=0.0063)$. However, the difference between the first follow-up visit and the latest followup visit was not statistically significant $(\mathrm{p}=0.42)$. At their first follow-up visit, 54\% of patients had a greater than $30 \%$ reduction in score, and $46 \%$ had a greater than $50 \%$ reduction in score. While most patients continued to have tics, an overall $50 \%$ improvement in terms of subjective impairment, motor, and vocal subscores of the YGTSS was observed in all patients, demonstrating significant correlations with overall improvement. The strongest correlation was with subjective impairment $(\mathrm{R}=0.9044)$, followed by motor tics $(\mathrm{R}=0.8654)$ and then vocal tics $(\mathrm{R}=$ 0.8575) (Fig. 2A-C).

The YBOCS scores were not calculated for all patients since some patients reported no or minimal OCD behaviors. However, when captured, the scores were compared preoperatively and postoperatively $(n=12)$. The difference between the scores was not significant between the preoperative and most recent postoperative YBOCS scores ( $\mathrm{p}=$ 0.033 ) at our alpha level of 0.01 . Though individual results varied, $63 \%$ of patients had a greater than $50 \%$ reduction in their YBOCS scores, while 1 patient experienced an increase in OCD behaviors (Fig. 2D).

In response to the 2-question survey, $100 \%$ of patients reported that they would rate their symptoms as either much improved or very much improved on the Clinical Global Impression scale. In addition, $100 \%$ of patients reported that knowing what they know about the procedure now, they would elect to have the surgery again.

\section{Stimulation Parameters and Lead Locations}

Stimulation parameters for each patient are listed in Table 2 . The majority $(9 / 13)$ of patients had programming in simple monopolar mode, while the others had programming in bipolar mode (Cases 1, 5, and 11) or double monopolar mode (Case 9). The coordinates of the lead tips and active contacts, as determined by postoperative image fusion, are displayed in Table 3 . The average active contact location localized to the junction of the posterior ventralis oralis internus (VOI)/anterior centromedian-parafascicular (CM-PF) complex (Fig. 3). There were no significant differences between the left and right side for either the lead tip or the active contact location. No significant correlations were observed between active contact coordinates and the degree of symptomatic improvement among patients (1-way ANOVA).

\section{Complications}

There were no postoperative hemorrhages or any other immediate postoperative surgical complications. Two patients experienced device-related complications, necessitating additional surgical intervention (Table 2). One patient experienced wound erosion and infection (methicillin-sensitive Staphylococcus aureus) at the connector site in the left parietal scalp 8 months postoperatively, necessitating removal of the left lead and generator, which was replaced 5 months later without adverse sequelae. In another patient, excessive manual manipulation of the right pulse genera- 

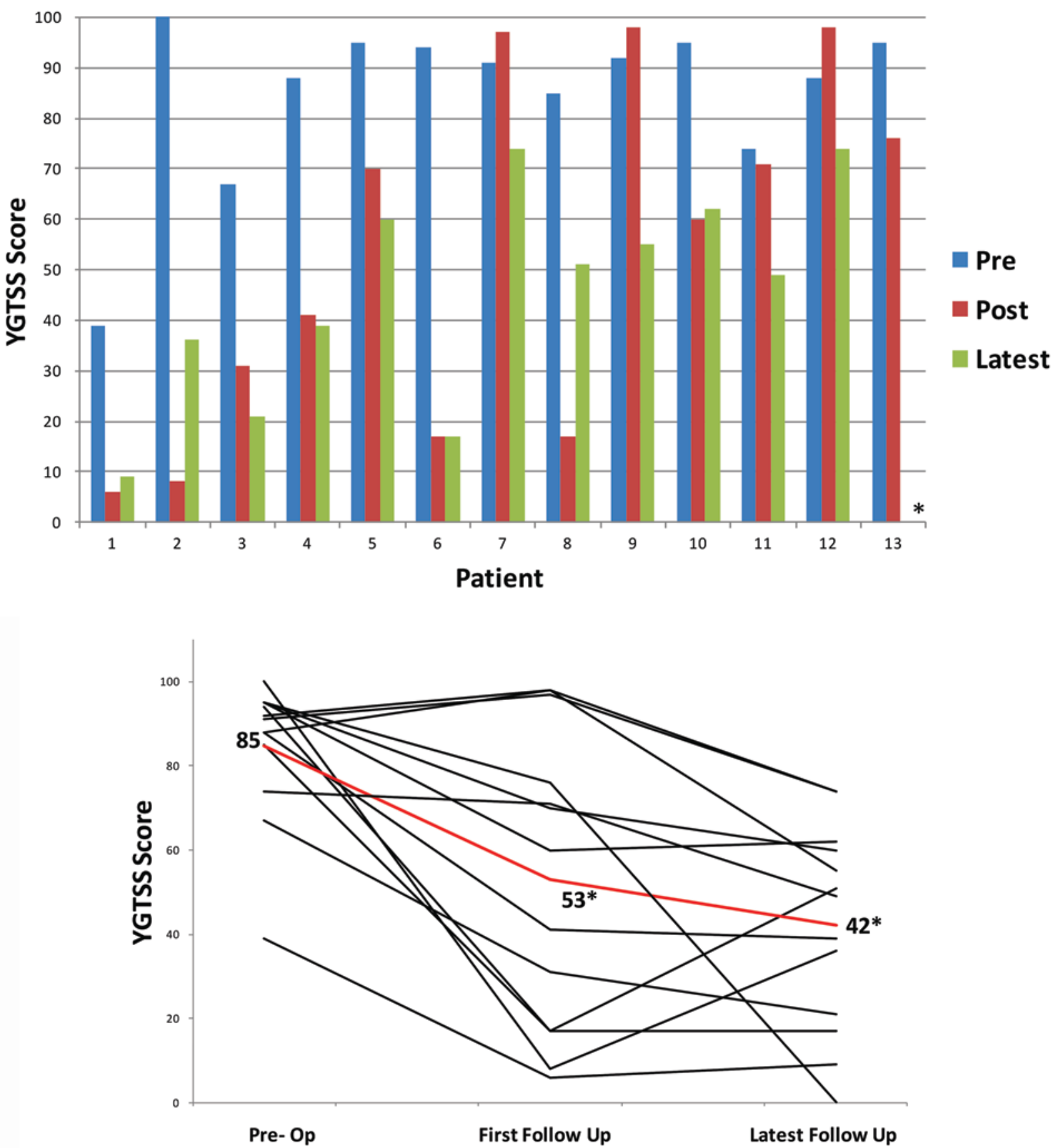

FIG. 1. Upper: Bar graph showing YGTSS scores preoperatively, immediately postoperatively, and at the latest follow-up compared using the Wilcoxon signed-rank test. The average difference from preoperatively to the first postoperative visit was $37 \%$ and was significant $(n=13, p=0.0063)$. The average difference from the preoperative to the latest score was $50 \%$ and was significant $(n=13, p=0.0015)$. By the first postoperative visit, $54 \%$ had a greater than $30 \%$ reduction and $46 \%$ had a greater than $50 \%$ reduction in their initial scores. By the latest follow-up, $84 \%$ had greater than $30 \%$ reduction and $55 \%$ had greater than $50 \%$ reduction of their initial scores. *YGTSS score of 0 . Lower: Line graph showing YGTSS score versus time for all patients $(n=13)$. Time point zero represents the preoperative scores. The 2 following time points represent follow-up appointments throughout the patient's treatment. The red line represents the average response. *Statistically significantly different from preoperative scores based on the Wilcoxon signed-rank test. Figure is available in color online only.

tor ("twiddler's syndrome") resulted in an extension lead fracture 10 months after system implantation as previously reported. The extension lead was replaced, but a postoperative infection developed 3 weeks later (organism: Pseudomonas aeruginosa), and the entire right-sided system was removed. It was reimplanted 4 months later, but the same right-sided system needed to be removed when an aseptic cyst developed at the lead tip 13 months later, resulting in headaches and mental status changes secondary to obstructive hydrocephalus. ${ }^{19}$ Upon removal of the entire 
A

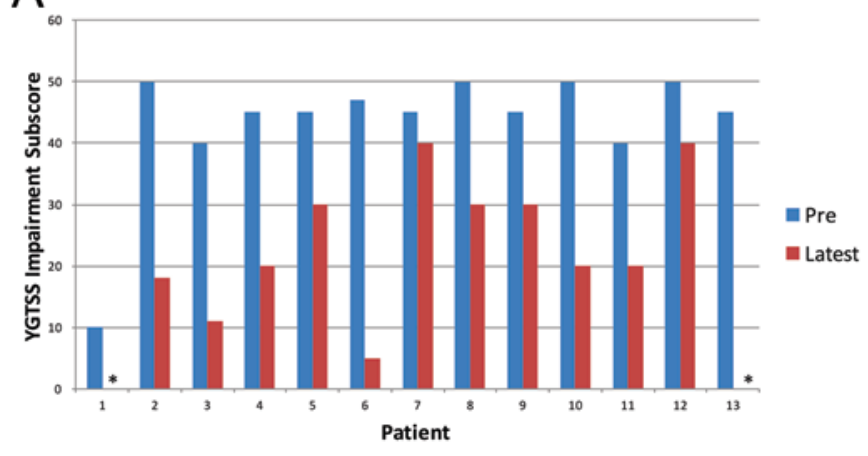

C

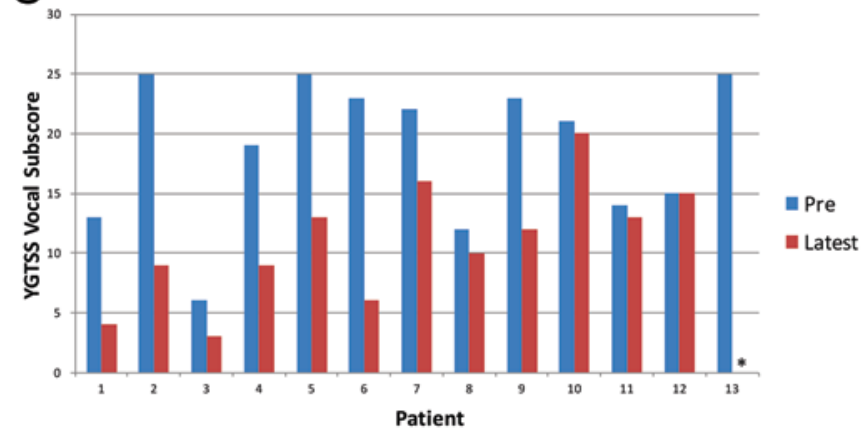

B

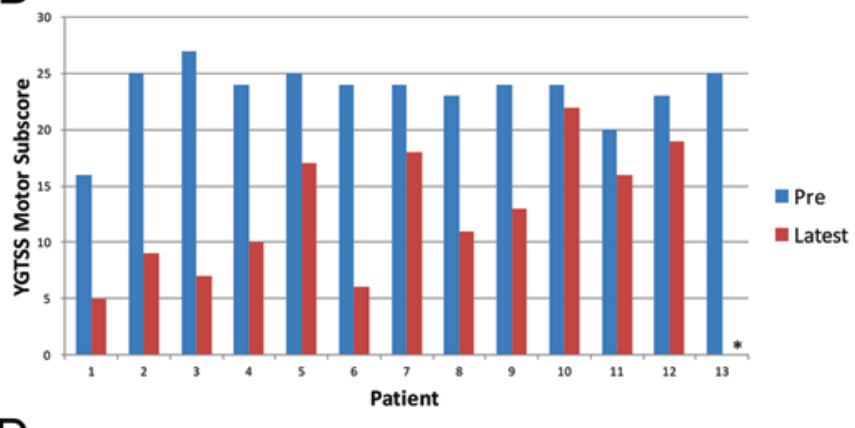

D

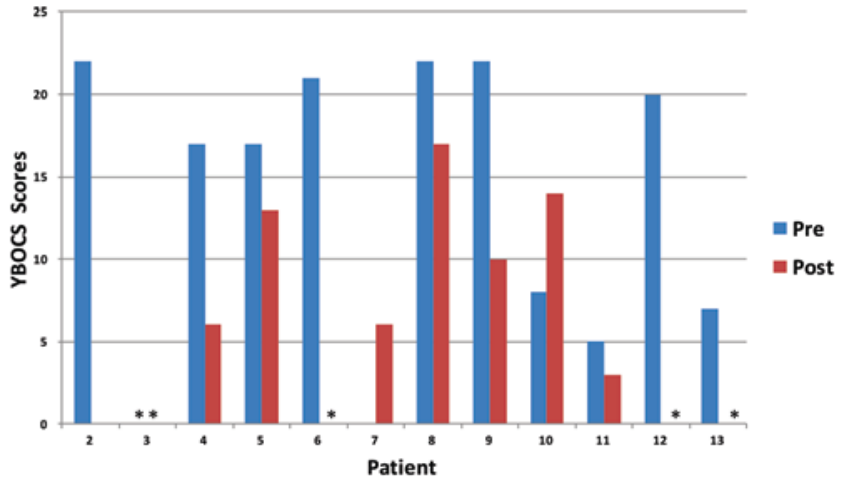

FIG. 2. A: Bar graph showing preoperative YGTSS impairment subscore versus the latest follow-up YGTSS impairment subscore. The average difference was $53 \%(p=0.0015)$. Sixty-two percent of patients had a greater than $50 \%$ reduction in their subjective impairment score by their latest follow-up visit. This showed a positive correlation with the overall YGTSS score $(R=0.9044, p=$ $0.000022)$. B: Bar graph showing the preoperative YGTSS motor subscore versus the latest follow-up subscore. The average difference was $50 \%(p=0.0018)$. Sixty-three percent of patients had greater than $50 \%$ reduction in their motor tic symptoms by their latest follow-up visit. This showed a positive correlation with the overall YGTSS score $(R=0.8654, p=0.00013)$. C: Bar graph showing preoperative YGTSS vocal subscore versus the latest follow-up vocal subscore. The average difference was 47\% ( $p=$ 0.0022 ). Forty-six percent of patients had greater than $50 \%$ reduction in their symptoms by their latest follow-up visit. This showed a positive correlation with the overall YGTSS score $(R=0.8575, p=0.00018)$. $D$ : Bar graph showing preoperative YBOCS score versus the latest follow-up YBOCS score. The average difference was $57 \%(p=0.033, n=12)$. Sixty-three percent of patients had greater than $50 \%$ reduction in their symptoms by their latest follow-up visit. One patient (Case 1) had no recorded YBOCS data and was not included in analysis, indicated by the lack of a bar. All comparisons were performed using the Wilcoxon signed-rank test. *A subscore/score of 0 . Figure is available in color online only.

system, the cyst regressed and the patient returned to her baseline condition, albeit with hemi-tics on the nonstimulated side. ${ }^{30}$

\section{Discussion}

Our findings further support that the CM-PF region is a consistently if not uniformly effective target for the treatment of TS. All patients demonstrated a response to the treatment with a reduction in symptoms, and on average they showed a significant $50 \%$ decrease in their YGTSS scores. These results are similar to other case series and observational studies, adding further support for the selective use of DBS to treat TS..$^{10,11,18,20,25,29,35}$ To our knowledge, only the case series published by Servello et al. ${ }^{37}$ and Porta et al..$^{29}$ involved a similar number of CM-PF DBS patients with long-term follow-up. These reports demonstrated a $47 \%$ and $73 \%$ mean reduction in the YGTSS, respectively.

One striking feature of the response is the variable latency of effect. Half of the patients demonstrated an immediate and marked improvement. While this could represent a placebo effect, the enduring benefit, maintained in some cases for years, suggests that the benefit is at least in part related to a "microlesion" effect. Similar immediate postoperative improvement has been reported in lesion-based surgical approaches for TS. ${ }^{5}$ The remaining patients required several months before experiencing a meaningful improvement, sometimes even without great changes in parameters. In this respect, the programming effect can be likened to that of dystonia, where improvement may be seen immediately or only after months. As in the double-blind GPI study reported by Kefalopoulou et al., ${ }^{20}$ improvement in the YGTSS score was most pronounced in the impairment subscore. Although this could be an artifact of the nature of the rating scale, which is more heavily weighted toward impairment, it suggests that improvement in social stress is not solely correlated with the raw change in motor or vocal tic scores. This may explain why even patients without a robust improvement in the overall YGTSS scores reported feeling either "improved" or "very much improved" on the Clinical Global Impression scale.

The overall benefit is also supported by answers to 
TABLE 2. Surgical details and medications for all 13 patients

\begin{tabular}{|c|c|c|c|c|c|c|c|}
\hline $\begin{array}{l}\text { Case } \\
\text { No. }\end{array}$ & Active Contact & $\begin{array}{l}\text { Current } \\
\text { Amplitude } \\
\text { (V) }\end{array}$ & $\begin{array}{l}\text { Current } \\
\text { Width } \\
\text { (usec) }\end{array}$ & $\begin{array}{l}\text { Current } \\
\text { Frequency } \\
(\mathrm{Hz})\end{array}$ & Complications & $\begin{array}{l}\text { Medications Tried \& Stopped Prior to DBS } \\
\text { (max doses if possible })^{*}\end{array}$ & Current Medications \\
\hline 1 & $\begin{array}{l}\mathrm{Lt}: 3+2-; \\
\quad \mathrm{rt}: 3+1-2-\end{array}$ & $\begin{array}{l}\text { Lt: } 3.2 \\
\text { rt: } 3.0\end{array}$ & $\begin{array}{l}\text { Lt: } 90 \\
\text { rt: } 90\end{array}$ & $\begin{array}{l}\text { Lt: } 130 \\
\quad \text { rt: } 130\end{array}$ & None & $\begin{array}{l}\text { Aripiprazole, lamotrigine, methylphenidate, ris- } \\
\text { peridone, sertraline, Topamax, ziprasidone }\end{array}$ & None \\
\hline 2 & $\begin{array}{l}\text { Lt: } C+1-; \\
\quad r t: C+1-\end{array}$ & $\begin{array}{l}\text { Lt: } 3.5 \\
\text { rt: } 3.5\end{array}$ & $\begin{array}{l}\text { Lt: } 90 ; \\
\text { rt: } 90\end{array}$ & $\begin{array}{l}\text { Lt: } 130 ; \\
\text { rt: } 130\end{array}$ & None & $\begin{array}{l}\text { Clonazepam, clonidine, fluphenazine, haloperi- } \\
\text { dol, levetiracetam, olanzapine, pimozide, } \\
\text { tetrabenazine, ziprasidone }\end{array}$ & None \\
\hline 3 & $\begin{array}{l}\text { Lt: } C+1-; \\
\text { rt: } C+9-\end{array}$ & $\begin{array}{l}\text { Lt: } 3.5 \\
\text { rt: } 3.5\end{array}$ & $\begin{array}{l}\text { Lt: } 90 ; \\
\text { rt: } 90\end{array}$ & $\begin{array}{l}\text { Lt: } 185 ; \\
\text { rt: } 185\end{array}$ & None & $\begin{array}{l}\text { Atomoxetine, botulinum toxin, clonazepam, } \\
\text { clonidine, guanfacine, haloperidol, olanzap- } \\
\text { ine, pimozide, risperidone }\end{array}$ & Pimozide \\
\hline 4 & Lt: C+ 2- & Lt: 4 & Lt: 90 & Lt: 130 & $\begin{array}{l}\text { 1) Lead fracture } \\
\text { on rt, } \\
\text { replacement; } \\
\text { 2) lead tip } \\
\text { cyst on rt, } \\
\text { removal }\end{array}$ & $\begin{array}{l}\text { Aripiprazole, botulinum toxin, clonazepam, } \\
\text { clonidine, haloperidol, risperidone }\end{array}$ & $\begin{array}{l}\text { Gabapentin, pimozide, } \\
\text { clomipramine, } \\
\text { lamotrigine }\end{array}$ \\
\hline 5 & $\begin{array}{l}\text { Lt: } 3+1-2- \\
\quad r t: 3+1-2-\end{array}$ & $\begin{array}{l}\text { Lt: } 3.0 ; \\
\text { rt: } 3.0\end{array}$ & $\begin{array}{l}\text { Lt: } 90 \\
\text { rt: } 90\end{array}$ & $\begin{array}{l}\text { Lt: } 130 \\
\quad \text { rt: } 130\end{array}$ & None & $\begin{array}{l}\text { Aripiprazole, clonazepam, guanfacine, haloper- } \\
\text { idol, risperidone, tetrabenazine, Topamax }\end{array}$ & Diazepam, benztropine \\
\hline 6 & $\begin{array}{l}\mathrm{Lt}: \mathrm{C}+2-; \\
\quad \mathrm{rt}: \mathrm{C}+2-\end{array}$ & $\begin{array}{l}\text { Lt: } 4.6 ; \\
\text { rt: } 4.6\end{array}$ & $\begin{array}{l}\text { Lt: } 210 ; \\
\text { rt: } 210\end{array}$ & $\begin{array}{l}\text { Lt: } 130 \\
\quad \text { rt: } 130\end{array}$ & None & $\begin{array}{l}\text { Clonazepam, clonidine, guanfacine, haloperi- } \\
\text { dol, pimozide, risperidone, ziprasidone }\end{array}$ & Aripiprazole \\
\hline 7 & $\begin{array}{l}\text { Lt: } \mathrm{C}+0-; \\
\text { rt: } \mathrm{C}+0-\end{array}$ & $\begin{array}{l}\mathrm{Lt}: 2.2 \\
\text { rt: } 2.0\end{array}$ & $\begin{array}{l}\text { Lt: } 120 ; \\
\text { rt: } 120\end{array}$ & $\begin{array}{l}\text { Lt: } 135 ; \\
\text { rt: } 135\end{array}$ & None & Aripiprazole, clonidine, pimozide, risperidone & $\begin{array}{l}\text { Carisoprodol, mari- } \\
\text { juana, sertraline, } \\
\text { tetrabenazine }\end{array}$ \\
\hline 8 & $\begin{array}{l}\mathrm{Lt}: \mathrm{C}+1-; \\
\quad \mathrm{rt}: \mathrm{C}+1-\end{array}$ & $\begin{array}{l}\text { Lt: } 0.6 \\
\text { rt: } 0.26\end{array}$ & $\begin{array}{l}\text { Lt: } 90 \\
\text { rt: } 90\end{array}$ & $\begin{array}{l}\text { Lt: } 130 \\
\quad \text { rt: } 130\end{array}$ & None & $\begin{array}{l}\text { Clonidine, desipramine, fluphenazine, haloperi- } \\
\text { dol, pimozide }\end{array}$ & $\begin{array}{l}\text { Ativan, clonazepam, } \\
\text { sertraline }\end{array}$ \\
\hline 9 & $\begin{array}{l}\mathrm{Lt}: \mathrm{C}+1-2-; \\
\quad \mathrm{rt}: \mathrm{C}+1-2-\end{array}$ & $\begin{aligned} \mathrm{Lt}: & 4.5 \\
\mathrm{rt}: & 4.5\end{aligned}$ & $\begin{array}{l}\text { Lt: } 90 \\
\text { rt: } 90\end{array}$ & $\begin{array}{l}\text { Lt: } 185 \\
\text { rt: } 185\end{array}$ & None & $\begin{array}{l}\text { Aripiprazole, guanfacine, haloperidol, olan- } \\
\text { zapine, paliperidone, pimozide, risperidone, } \\
\text { ziprasidone }\end{array}$ & $\begin{array}{l}\text { Clomipramine, clon- } \\
\text { azepam, clonidine, } \\
\text { perphenazine, } \\
\text { venlafaxine }\end{array}$ \\
\hline 10 & $\begin{array}{l}\text { Lt: } C+1-; \\
\text { rt: } C+1-\end{array}$ & $\begin{array}{l}\text { Lt: } 3.7 \\
\text { rt: } 3.5\end{array}$ & $\begin{array}{l}\text { Lt: } 90 ; \\
\text { rt: } 90\end{array}$ & $\begin{array}{l}\text { Lt: } 145 ; \\
\text { rt: } 145\end{array}$ & None & $\begin{array}{l}\text { Aripiprazole, atomoxetine, clonidine, fluphen- } \\
\text { azine, guanfacine, haloperidol, risperidone }\end{array}$ & None \\
\hline 11 & $\begin{array}{l}\mathrm{Lt}: 0+1-2-; \\
\text { rt: } 3+1-2-\end{array}$ & $\begin{array}{l}\text { Lt: } 3.5 ; \\
\text { rt: } 3.5\end{array}$ & $\begin{array}{r}\text { Lt: } 120 ; \\
\text { rt: } 90\end{array}$ & $\begin{array}{l}\text { Lt: } 130 ; \\
\text { rt: } 130\end{array}$ & $\begin{array}{l}\text { Wound infec- } \\
\text { tion on It, } \\
\text { removal }\end{array}$ & $\begin{array}{l}\text { Aripiprazole, clonazepam, guanfacine, halo- } \\
\text { peridol, perphenazine, pimozide, quetiapine, } \\
\text { risperidone, tetrabenazine, trazodone }\end{array}$ & $\begin{array}{l}\text { Clonazepam, clonidine, } \\
\text { escitalopram, que- } \\
\text { tiapine, risperidone }\end{array}$ \\
\hline 12 & $\begin{array}{l}\text { Lt: } C+1-; \\
\text { rt: } C+1-\end{array}$ & $\begin{array}{l}\text { Lt: } 3.2 ; \\
\text { rt: } 3.2\end{array}$ & $\begin{array}{l}\text { Lt: } 90 ; \\
\text { rt: } 90\end{array}$ & $\begin{array}{l}\text { Lt: } 130 ; \\
\text { rt: } 130\end{array}$ & None & $\begin{array}{l}\text { Citalopram, clonidine, clorazepate, donepezil, } \\
\text { fluoxetine, fluphenazine, risperidone, tetra- } \\
\text { benazine, Topamax, ziprasidone }\end{array}$ & $\begin{array}{l}\text { Benztropine, clonaz- } \\
\text { epam, fluoxetine, } \\
\text { guanfacine, loraz- } \\
\text { epam, pimozide }\end{array}$ \\
\hline 13 & $\begin{array}{l}\text { Lt: } \mathrm{C}+1-; \\
\quad \mathrm{rt}: \mathrm{C}+1-\end{array}$ & $\begin{array}{l}\text { Lt: } 1.0 \\
\text { rt: } 1.0\end{array}$ & $\begin{array}{l}\text { Lt: } 90 \\
\text { rt: } 90\end{array}$ & $\begin{array}{l}\text { Lt: } 130 \\
\quad \text { rt: } 130\end{array}$ & None & $\begin{array}{l}\text { Clonazepam, clonidine, methylphenidate, } \\
\text { pimozide, risperidone, sertraline, Topamax }\end{array}$ & Diazepam \\
\hline
\end{tabular}

* Each patient was screened for a number of psychiatric comorbidities. Careful documentation was kept regarding the failed therapies for each patient.

the 2-question survey, which was administered at least 6 months after the procedure. All patients reported either much improved or very much improved symptoms on the Clinical Global Impression scale. In addition, all patients would be willing to have the surgery again, knowing what they know now, even those patients who had complications or experienced relatively less robust responses. Both patients who required hardware removal for infections experienced a significant increase in tics and were eager to have the DBS device reimplanted as soon as possible.

Approximately two-thirds of patients (63\%) experienced some improvement in OCD symptoms as corroborated by YBOCS scores, with the overall group experienc- ing an average reduction of $57 \%$ over their preoperative scores. This did not achieve significance with our alpha cutoff of 0.01 , but did trend toward significance. This is also consistent with the currently available literature on DBS for TS using the CM-PF as the target, although Bajwa et al. and Servello et al. reported more robust improvement in OCD scores. ${ }^{6,36}$

As mentioned above, the most ventral, best tolerated contact was selected for therapy. In most patients, stimulation of the most ventral/deepest contact ( 0 left, 4 right) resulted in untoward side effects, and thus Contact 1 left $/ 5$ right was most commonly used. Thus, the average stimulation zone maps to the VOI/CM-PF junction, consistent 
TABLE 3. The stereotactic coordinates for distal contacts (center of Contact 0 ) and active contacts in all patients

\begin{tabular}{|c|c|c|c|c|c|c|c|c|c|c|c|c|c|c|}
\hline \multirow{3}{*}{$\begin{array}{c}\text { Case } \\
\text { No. }\end{array}$} & \multirow{3}{*}{$\begin{array}{c}\mathrm{Lt} \\
\text { Contact }\end{array}$} & \multirow{3}{*}{$\begin{array}{c}\mathrm{Rt} \\
\text { Contact }\end{array}$} & \multicolumn{6}{|c|}{ Lt Lead $^{*}$} & \multicolumn{6}{|c|}{ Rt Lead* } \\
\hline & & & \multicolumn{3}{|c|}{ Lead Tip } & \multicolumn{3}{|c|}{ Active Contact $†$} & \multicolumn{3}{|c|}{ Lead Tip } & \multicolumn{3}{|c|}{ Active Contact $†$} \\
\hline & & & $x$ & y & z & $x$ & y & z & $x$ & y & z & $x$ & y & z \\
\hline 1 & 2 & 1,2 & 3.4 & -8.0 & -2.0 & 6.0 & -4.4 & 2.2 & 2.7 & -7.5 & -1.0 & 5.3 & -5.2 & 2.0 \\
\hline 2 & 1 & 1 & 5.0 & -4.6 & -1.1 & 6.2 & -2.8 & 0.6 & 4.2 & -4.4 & -1.4 & 5.2 & -2.7 & 1.0 \\
\hline 3 & 1 & 1 & 4.7 & -4.7 & 0.4 & 6.0 & -3.2 & 2.6 & 5.7 & -3.7 & 1.0 & 7.1 & -2.7 & 3.5 \\
\hline 4 & 2 & NA & 5.0 & -4.1 & -2.0 & 7.7 & -1.0 & 2.6 & 5.3 & -4.1 & -1.2 & NA & NA & NA \\
\hline 5 & 2 & 2 & 5.3 & -3.7 & -0.2 & 7.8 & -0.2 & 4.5 & 4.7 & -3.6 & -1.2 & 7.3 & -0.3 & 3.7 \\
\hline 6 & 2 & 2 & 5.2 & -3.0 & -0.1 & 8.4 & -0.6 & 4.5 & 4.8 & -3.5 & -0.2 & 7.4 & -0.7 & 4.8 \\
\hline 7 & 1 & 1 & 5.3 & -3.2 & -0.4 & 7.0 & -1.9 & 2.1 & 4.2 & -3.9 & 0.0 & 5.4 & -2.6 & 2.5 \\
\hline 8 & 1 & 1 & 5.8 & -3.6 & -0.8 & 7.4 & -1.9 & 1.5 & 4.2 & -3.9 & 0.2 & 5.6 & -2.1 & 2.1 \\
\hline 9 & 1,2 & 1,2 & 5.3 & -4.0 & 0.1 & 7.5 & -1.4 & 3.6 & 4.5 & -3.5 & 0.1 & 7.5 & -1.4 & 3.6 \\
\hline 10 & 1 & 1 & 4.2 & -4.1 & 1.0 & 5.8 & -2.2 & 3.5 & 5.0 & -4.3 & 0.2 & 5.8 & -2.2 & 3.5 \\
\hline 11 & 1,2 & 1,2 & 4.4 & -4.2 & 0.6 & 6.5 & -2.4 & 4.4 & 4.3 & -4.1 & -0.9 & 6.5 & -2.4 & 4.4 \\
\hline 12 & 1 & 1 & 4.9 & -3.6 & -0.4 & 6.5 & -2.2 & 2.1 & 4.8 & -3.0 & -0.1 & 6.5 & -2.2 & 2.1 \\
\hline 13 & 1 & 1 & 4.0 & -3.4 & -0.1 & 5.7 & -2.0 & 2.3 & 4.9 & -3.4 & 0.3 & 5.7 & -2.0 & 2.3 \\
\hline Mean & & & 4.8 & -4.2 & -0.4 & 6.8 & -2.0 & 2.8 & 4.6 & -4.1 & -0.3 & 6.3 & -2.2 & 3.0 \\
\hline
\end{tabular}

$\mathrm{NA}=$ not applicable.

* Values represent stereotactic coordinates.

$\dagger$ The active contact was calculated as the average of the 2 cathodes in patients undergoing dual cathodic stimulation (Cases 1, 5, 9, and 11).

with the published literature. No apparent differences in the region of stimulation were observed between those with greater and lesser degrees of improvement.

The results of this observational study, like most of the DBS TS literature at this time, are limited by virtue of the small size and lack of randomization, blinding, or control group. Moreover, the variable nature of tics over time, compared with the progressive nature of Parkinson's disease, further clouds the impact of DBS in TS. We cannot exclude the possibility that some patients may have experienced an improvement in tic severity over time even without DBS. The worsening and subsequent improvement in tics following device malfunction and revision, as previously reported in 1 patient, provides at least anecdotal evidence that stimulation plays a continuing role in long term-symptom control. ${ }^{30}$ These limitations continue to

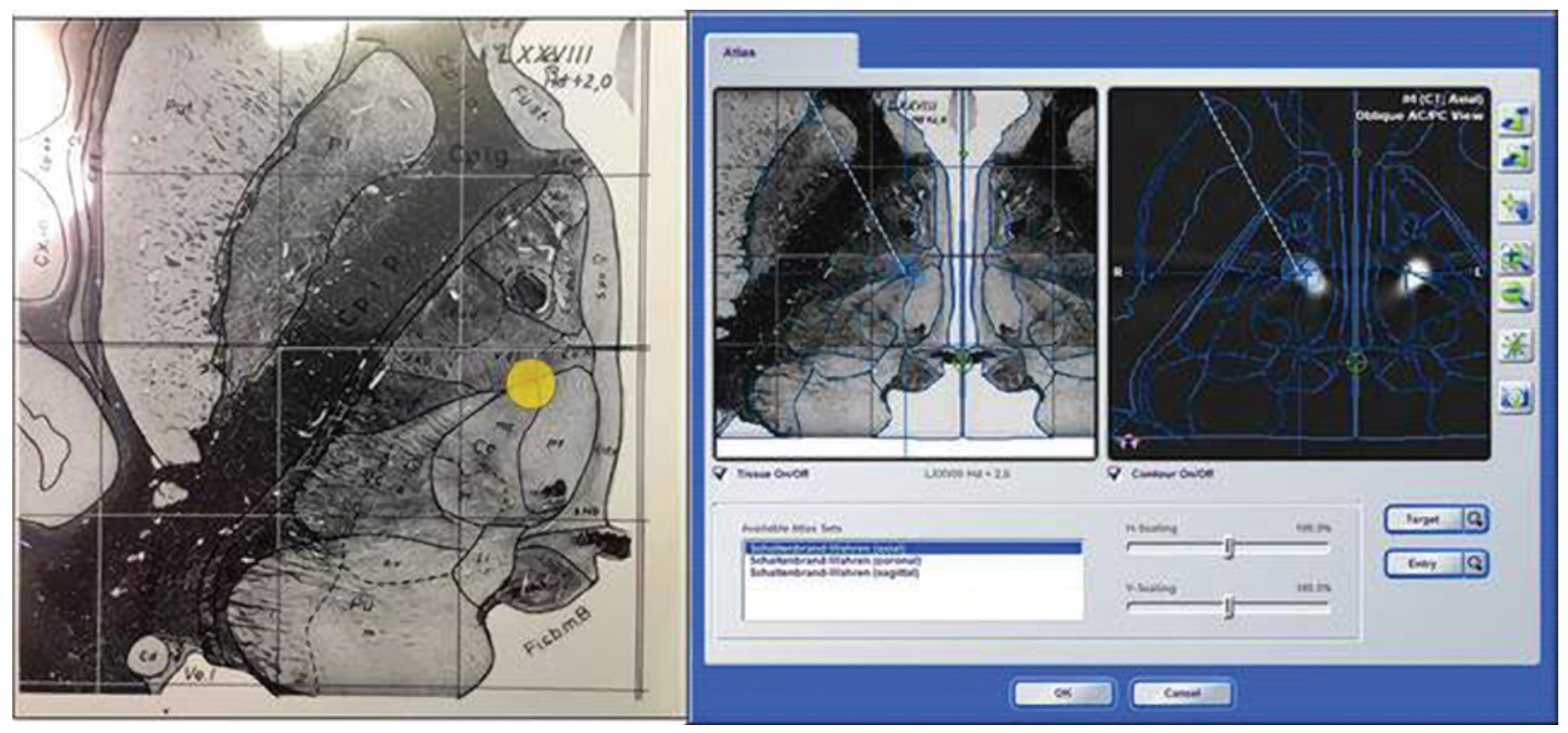

FIG. 3. Image from the Schaltenbrand and Wahren stereotactic atlas, axial slice at $2.0 \mathrm{~mm}$ above the anterior commissure-posterior commissure plane. The yellow dot represents the average area of stimulation as calculated using the postoperative imaging studies. Figure is available in color online only. 
prove to be a vexing challenge in establishing consensus and approval for DBS. Until such time when a multicenter study proves feasible, however, case series demonstrating efficacy and safety over long periods of time provide added support for DBS in severe, refractory cases of TS. The small size is partially compensated for by the large effect size demonstrated in this and other studies of DBS for TS. Of particular note with this cohort is the relatively young age of several patients (mean 20 years, range 16-33 years) compared with other publications and with the mean age of 29 years in the multicenter Tourette's DBS database. ${ }^{27}$ The appropriate minimum age to pursue DBS in TS, which may attenuate with time, remains an area of debate, as reflected in changing recommendations by consensus committees. Suggested guidelines published in 2006 recommended a minimum age of 25 years, ${ }^{26}$ whereas more recently proposed guidelines did not provide a cutoff but rather recommend "local ethics committee involvement" for patients younger than 18 years. ${ }^{35}$ Our medical rationale for inclusion of patients as young as 16 years old was one of benefit versus risk, where tics were so violent as to result in numerous hospitalizations as well as resultant social isolation, including an inability to drive or attend school. Establishing the appropriate minimum age for DBS in TS will likely remain an area of debate. Another important and unresolved question involves the optimal target for TS literature, demonstrating variable efficacy for a number of targets, predominantly focusing on the medial thalamus and globus pallidus.

The most recent large case series reported by Servello et al. ${ }^{37}$ was notable for a high rate of device removal (11 of the original 48 device implants) due to "inflammatory complications or poor compliance." As mentioned, devicerelated complications, including infection and extension lead fracture, occurred in 2 of our patients, with 1 patient requiring 3 revisions over a 5-year period for extension lead fracture secondary to "twiddler's syndrome." This phenomenon (extension lead fracture) occurred despite the generator being replaced in a subpectoral pocket as described by Servello and colleagues. ${ }^{39}$ Our experience reinforces the perception that DBS for TS may be associated with a higher incidence of such complications when compared with other traditional indications for DBS. That the complication rate in a recent GPI TS cohort was $13 \% \%^{20}$ suggests that complication rates are not target specific but more of an inherent challenge within this patient population.

\section{Conclusions}

This study adds to the growing, but still small, body of literature regarding DBS for TS. It is also notable for the younger age of the cohort, which remains an area of debate regarding inclusion/exclusion criteria. This series, which follows patients for as long as 7 years after DBS, supports the potential for CM-PF DBS to improve severe, refractory TS symptoms with relatively few significant side effects. This retrospective, observational study, like many other DBS TS reports, is limited by its nonrandomized, nonblinded nature and by the relatively small sample size. Clearly, a large, multicenter trial would be preferable, but innumerable challenges make such an eventuality unlikely. Until such time, larger case series provide support that DBS of the CM-PF is an effective and safe treatment for TS.

\section{References}

1. Ackermans L, Duits A, van der Linden C, Tijssen M, Schruers K, Temel Y, et al: Double-blind clinical trial of thalamic stimulation in patients with Tourette syndrome. Brain 134:832-844, 2011

2. Ackermans L, Neuner I, Temel Y, Duits A, Kuhn J, VisserVandewalle V: Thalamic deep brain stimulation for Tourette syndrome. Behav Neurol 27:133-138, 2013

3. Anderson D, Kartha N: Deep brain stimulation in nonparkinsonian movement disorders and emerging technologies, targets, and therapeutic promises in deep brain stimulation. Neurol Clin 31:809-826, 2013

4. Asazuma T, Toyama Y, Watanabe M, Suzuki N, Fujimura Y, Hirabayashi K: Clinical features associated with recurrence of tumours of the spinal cord and cauda equina. Spinal Cord 41:85-89, 2003

5. Babel TB, Warnke PC, Ostertag CB: Immediate and long term outcome after infrathalamic and thalamic lesioning for intractable Tourette's syndrome. J Neurol Neurosurg Psychiatry 70:666-671, 2001

6. Bajwa RJ, de Lotbinière AJ, King RA, Jabbari B, Quatrano S, Kunze K, et al: Deep brain stimulation in Tourette's syndrome. Mov Disord 22:1346-1350, 2007

7. Burd L, Kerbeshian PJ, Barth A, Klug MG, Avery PK, Benz B: Long-term follow-up of an epidemiologically defined cohort of patients with Tourette syndrome. J Child Neurol 16:431-437, 2001

8. Cannon E, Silburn P, Coyne T, O’Maley K, Crawford JD, Sachdev PS: Deep brain stimulation of anteromedial globus pallidus interna for severe Tourette's syndrome. Am J Psychiatry 169:860-866, 2012

9. Dehning S, Leitner B, Schennach R, Müller N, Bötzel K, Obermeier M, et al: Functional outcome and quality of life in Tourette's syndrome after deep brain stimulation of the posteroventrolateral globus pallidus internus: long-term followup. World J Biol Psychiatry 15:66-75, 2014

10. DeLong M, Wichmann T: Deep brain stimulation for movement and other neurologic disorders. Ann N Y Acad Sci 1265:1-8, 2012

11. Dueck A, Wolters A, Wunsch K, Bohne-Suraj S, Mueller JU, Haessler F, et al: Deep brain stimulation of globus pallidus internus in a 16-year-old boy with severe Tourette syndrome and mental retardation. Neuropediatrics 40:239-242, 2009

12. Flaherty AW, Williams ZM, Amirnovin R, Kasper E, Rauch SL, Cosgrove GR, et al: Deep brain stimulation of the anterior internal capsule for the treatment of Tourette syndrome: technical case report. Neurosurgery 57 (4 Suppl):E403, 2005

13. Ganos C, Roessner V, Münchau A: The functional anatomy of Gilles de la Tourette syndrome. Neurosci Biobehav Rev 37:1050-1062, 2013

14. Goodman WK, Price LH, Rasmussen SA, et al: The YaleBrown Obsessive-Compulsive Scale. I. Development, use, and reliability. Arch Gen Psychiatry 46:1006-1011, 1989

15. Guy W: Clinical global impressions, in ECDEU Assessment Manual for Psychopharmacology-Revised. Rockville, MD: U.S. Department of Health, Education, and Welfare

16. Hariz MI, Robertson MM: Gilles de la Tourette syndrome and deep brain stimulation. Eur J Neurosci 32:1128-1134, 2010

17. Jankovic J (ed): Neurologic Clinics. Tourette Syndrome. Philadelphia: W.B. Saunders, 1997, Vol 15

18. Kaido T, Otsuki T, Kaneko Y, Takahashi A, Omori M, Oka- 
moto T: Deep brain stimulation for Tourette syndrome: a prospective pilot study in Japan. Neuromodulation 14:123-129, 2011

19. Katlowitz K, Pourfar MH, Israel Z, Mogilner AY: Intraparenchymal cysts following deep brain stimulation: variable presentations and clinical courses. Oper Neurosurg [in press], 2016

20. Kefalopoulou Z, Zrinzo L, Jahanshahi M, Candelario J, Milabo C, Beigi M, et al: Bilateral globus pallidus stimulation for severe Tourette's syndrome: a double-blind, randomised crossover trial. Lancet Neurol 14:595-605, 2015

21. Kuhn J, Bartsch C, Lenartz D, Huys D, Daumann J, Woopen $\mathrm{C}$, et al: Clinical effectiveness of unilateral deep brain stimulation in Tourette syndrome. Transl Psychiatry 1:e52, 2011

22. Leckman JF, Peterson BS, Anderson GM, Arnsten AFT, Pauls DL, Cohen DJ: Pathogenesis of Tourette's syndrome. J Child Psychol Psychiatry 38:119-142, 1997

23. Leckman JF, Riddle, MA. Hardin MT, Ort SI, Swartz KL, Stevenson J, Cohen, DJ: The Yale Global Tic Severity Scale: initial testing of a clinician-rated scale of tic severity. J Am Acad Child Adolesc Psychiatry 28: 566-573, 1989

24. Lee MWY, Au-Yeung MM, Hung KN, Wong CK: Deep brain stimulation in a Chinese Tourette's syndrome patient. Hong Kong Med J 17:147-150, 2011

25. Martínez-Fernández R, Zrinzo L, Aviles-Olmos I, Hariz M, Martinez-Torres I, Joyce E, et al: Deep brain stimulation for Gilles de la Tourette syndrome: a case series targeting subregions of the globus pallidus internus. Mov Disord 26:19221930, 2011

26. Mink JW, Walkup J, Frey KA, Como P, Cath D, Delong MR, et al: Patient selection and assessment recommendations for deep brain stimulation in Tourette syndrome. Mov Disord 21:1831-1838, 2006

27. Mogilner AY, Pourfar M, Deeb W, Rizer K, Rossi J, Dowd R, et al: International Tourette's syndrome deep brain stimulation registry and database. Stereotact Funct Neurosurg 94 (Suppl 2):50, 2017 (Abstract)

28. Porta M, Saleh C, Zekaj E, Zanaboni Dina C, Bona AR, Servello D: Why so many deep brain stimulation targets in Tourette's syndrome? Toward a broadening of the definition of the syndrome. J Neural Transm (Vienna) 123:785-790, 2016 [Erratum in J Neural Transm (Vienna) 123:1355, 2016]

29. Porta M, Servello D, Zanaboni C, Anasetti F, Menghetti C, Sassi M, et al: Deep brain stimulation for treatment of refractory Tourette syndrome: long-term follow-up. Acta Neurochir (Wien) 154:2029-2041, 2012

30. Pourfar M, Budman C, Mogilner A: A case of deep brain stimulation in Tourette's complicated by twiddler's syndrome. Mov Disord Clin Pract 2:192-193, 2015

31. Pourfar M, Feigin A, Tang CC, Carbon-Correll M, Bussa M, Budman C, et al: Abnormal metabolic brain networks in Tourette syndrome. Neurology 76:944-952, 2011

32. Rickards H, Wood C, Cavanna AE: Hassler and Dieckmann's seminal paper on stereotactic thalamotomy for Gilles de la Tourette syndrome: translation and critical reappraisal. Mov Disord 23:1966-1972, 2008

33. Sachdev PS, Mohan A, Cannon E, Crawford JD, Silberstein P, Cook R, et al: Deep brain stimulation of the antero-medial globus pallidus interna for Tourette syndrome. PLoS One 9:e104926, 2014

34. Schoenberg MR, Maddux BN, Riley DE, Whitney CM, Ogrocki PK, Gould D, et al: Five-months-postoperative neuropsychological outcome from a pilot prospective randomized clinical trial of thalamic deep brain stimulation for Tourette syndrome. Neuromodulation 18:97-104, 2015

35. Schrock LE, Mink JW, Woods DW, Porta M, Servello D, Visser-Vandewalle V, et al: Tourette syndrome deep brain stimulation: a review and updated recommendations. Mov Disord 30:448-471, 2015

36. Servello D, Sassi M, Brambilla A, Defendi S, Porta M: Longterm, post-deep brain stimulation management of a series of 36 patients affected with refractory Gilles de la Tourette syndrome. Neuromodulation 13:187-194, 2010

37. Servello D, Zekaj E, Saleh C, Lange N, Porta M: Deep brain stimulation in Tourette syndrome: what does the future hold? A cohort of 48 patients. Neurosurgery 78:91-100, 2016

38. Servello D, Zekaj E, Saleh C, Zanaboni Dina C, Porta M: Sixteen years of deep brain stimulation in Tourette's syndrome: a critical review. J Neurosurg Sci 60:218-229, 2016

39. Servello D, Zekaj E, Sassi M, Menghetti C, Porta M: Submuscular submammarian internal pulse generator implantation in a patient with Tourette's syndrome and obsessive compulsive behavior. Neuromodulation 17:96-97, 2014

40. Smeets AY, Duits AA, Plantinga BR, Leentjens AF, Oosterloo M, Visser-Vandewalle V, et al: Deep brain stimulation of the internal globus pallidus in refractory Tourette syndrome. Clin Neurol Neurosurg 142:54-59, 2016

41. Tanner CM, Goldman SM: Epidemiology of Tourette syndrome. Neurol Clin 15:395-402, 1997

42. Zabek M, Sobstyl M, Koziara H, Dzierzecki S: Deep brain stimulation of the right nucleus accumbens in a patient with Tourette syndrome. Case report. Neurol Neurochir Pol 42:554-559, 2008

\section{Disclosures}

Dr. Pourfar reports that he is a consultant for and has received teaching honoraria from Medtronic Neurological. Dr. Mogilner reports that he is a consultant for and has received honoraria and grant support from Medtronic Neurological and is a consultant for Alpha Omega Engineering.

\section{Author Contributions}

Conception and design: all authors. Acquisition of data: Dowd. Analysis and interpretation of data: all authors. Drafting the article: all authors. Critically revising the article: all authors. Reviewed submitted version of manuscript: all authors. Statistical analysis: Dowd. Administrative/technical/material support: Dowd. Study supervision: Mogilner, Dowd.

\section{Supplemental Information}

\section{Previous Presentations}

Portions of this paper were presented in abstract/poster form at the American Society for Stereotactic and Functional Neurosurgery Biennial Meeting, May 31-June 3, 2014, in Washington, DC, and at the International Congress of Parkinson's Disease and Movement Disorders, June 14-18, 2015, in San Diego, CA.

\section{Correspondence}

Alon Mogilner, Department of Neurosurgery New York University Langone Medical Center, 550 First Ave., SKI-8S, New York, NY, 10016. email: alon.mogilner@nyumc.org. 